Vol 12, Issue 8, 2019

\title{
SMARTPHONE ADDICTION AND ITS RELATIONSHIP WITH PSYCHOLOGICAL HEALTH AMONG STUDENTS OF A MEDICAL SCHOOL IN EAST COAST MALAYSIA
}

\author{
AZWANIS ABDUL HADI ${ }^{*}$, HAWARI MUSYIR MOHD NAWAWI ${ }^{1}$, NURAFIFAH SHAMSURI ${ }^{1}$, \\ NURUL NAJIHAH RAHIM ${ }^{1}$, HAFIZAH PASI ${ }^{2}$
}

${ }^{1}$ Department of Family Medicine, International Islamic University Malaysia, Kuantan, Malaysia. ${ }^{2}$ Department of Community Medicine, International Islamic University Malaysia, Kuantan, Malaysia. Email: azwanis@iium.edu.my

Received: 31 May 2019, Revised and Accepted: 11 July 2019

ABSTRACT

Objective: Smartphones have now become a common and almost essential tool in our daily living activities. Students are among those who use smartphones regularly, which could lead to addiction if overused. This study aims to measure the prevalence of smartphone addiction and its relationship with psychological health among clinical year medical students in International Islamic University Malaysia (IIUM), Kuantan.

Methods: A total of 226 medical students in their clinical years were recruited through quota sampling method. The students filled in a four-part online-based questionnaire consisted of questions on sociodemographic characteristics, smartphone usage information, smartphone addiction scaleshort version, and WHOQOL-BREF. Data were analyzed using IBM SPSS Statistics.

Results: The prevalence of smartphone addiction among clinical year medical students in IIUM was 51\%. Bivariate analysis showed that the majority of students chose social networking as their primary purpose of using a smartphone, and this was significantly associated with smartphone addiction $(\mathrm{p}=0.037)$. Following multiple logistic regression analysis, students who had chosen games as their primary purpose of smartphone users are $88 \%$ less likely to be related with smartphone addiction ( $\mathrm{p}=0.009,95 \%$ CI: $0.025-0.595$ ) as compared to those who used it for academic performance tasks. Students who were not addicted to smartphones reported significantly better psychological quality of life compared to those who were addicted ( $\mathrm{p}<0.001)$.

Conclusion: Half of IIUM's medical students in clinical years was found to have smartphone addiction, and those with smartphone addiction had poor psychological health. Immediate intervention such as creating awareness in the campus is important in curbing this problem.

Keywords: Smartphone, Addiction, Medical students, Clinical year, Psychological health, Malaysia.

(c) 2019 The Authors. Published by Innovare Academic Sciences Pvt Ltd. This is an open access article under the CC BY license (http://creativecommons. org/licenses/by/4. 0/) DOI: http://dx.doi.org/10.22159/ajpcr.2019.v12i8.34396

\section{INTRODUCTION}

The advancing technology of smartphones has attracted every generation, including students at the level of tertiary education. The usage of smartphones, however, can lead to its problematic use and addiction, which might affect one's psychological well-being [1]. A smartphone according to Oxford dictionary (2017) is a mobile phone that performs many of the functions of a computer, typically having a touchscreen interface, internet access, and an operating system capable of running downloaded apps. While addiction is defined by the American Psychiatric Association, as the status of not being able to rationally judge or distinguish due to certain ideas or objects. Certain behaviors can induce short-term reward, which might turn into perpetual behavior despite awareness of having reduced control over the behavior, which is a fundamental concept of addiction. This equivalence brings up the idea of non-substance or "behavioral" addictions [2]. Thus, smartphone addiction may be defined here as having diminished control over its usage despite knowing its deleterious consequences.

The World Health Organization, WHO (2014) defines psychological or mental health as a state of well-being in which every individual realizes his or her potential, can cope with the normal stresses of life, can work productively and fruitfully, and is able to make a contribution to her or his community.

In Malaysia, a survey in 2017 by Malaysian Communications and Multimedia Commission shows mobile cellular penetration rates of $131.8 \%$ which is more compared to Spain where the penetration rate is $108.5 \%$. A large group of mobile users is college or university students in which they made up $53.3 \%$ compared to other schooling status.
Smartphone addiction is linked to various psychological complications, for example, anxiety, depression, insomnia, poor cognition, and low self-esteem $[3,4]$. Overdependence on smartphones brings stress and compulsive use of it which is a vicious cycle [1].

\section{METHODS}

\section{Ethical consideration}

Ethical approval was obtained from the Ethical Committee of International Islamic University Malaysia [IREC 2018-216].

Study design, population, and sampling method

This is a cross-sectional study which was carried out in Kulliyyah of Medicine, International Islamic University of Malaysia (IIUM), Kuantan Campus. The study was conducted from July 16, 2018, to August 24, 2018. A total of 226 IIUM medical students from $3^{\text {rd }}$ to $5^{\text {th }}$ year participated in this study. Quota sampling was used for the selection of participants where the data collection is done until the number of participants reaches the sample size calculated based on the quota. The representative of each year of study was approached and the link to an online-based questionnaire which is to be filled by the participants was distributed through WhatsApp application.

\section{Study tool}

The questionnaire was divided into four parts; the first part was the socio-demographic questions. The second part comprised questions regarding the participants' usage information and the third part consisted of the smartphone addiction scale-short version, a validated structured questionnaire with Cronbach's alpha value of 0.966 [5]. The fourth part consisted of the psychological domain of the WHO Quality of Life Assessment-Brief Version (WHOQOL-BREF). 
Statistical analysis

Data were then entered and analyzed using IBM SPSS Statistics for Windows version 23.0. Fisher's exact, Independent t-test, and MannWhitney U-test were used for bivariate analysis. Then, multiple logistic regressions were done for multivariate analysis. Significant level was determined at $95 \%$ confidence intervals with $\mathrm{p}<0.05$.

\section{RESULTS}

The mean age of the students was 24 years old (SD: 1.01 years), and onethird of the respondents was female $(70.8 \%)$. The majority of them were year 4 medical students (37.2\%) followed by an equal amount of year 3 and year 5 students (31.4\%). The median household income of the students was RM5000 (IQR: RM7000) while their median monthly expenditure relating to smartphones was RM40 (IQR: RM20). A total of 156 (69.0\%) students used smartphones primarily for social networking, and only $4.9 \%$ listed other purposes besides the options given as their answer. Out of the 226 students, slightly more than one-third of them spent 3-4 h using their smartphones $(36.7 \%)$ while only a mere $1.7 \%$ spent $<1$ h using their smartphones. Table 1 shows the socio-demographic data of the students.

\section{Prevalence of smartphone addiction}

The prevalence of smartphone addiction among medical students in IIUM was $51 \%$.

Psychological health of the clinical year students in Kulliyyah of medicine

The quality of life of year 4 medical students in terms of psychological health was better as evidenced by a calculated mean score of 61.33 (SD: 16.49), followed by year 5 and year 3 with mean scores of 60.34 (SD: 14.40) and 57.73 (SD: 10.05), respectively, as shown in Table 2.

Table 1: Socio-demographics of clinical year students of Kulliyyah of medicine of IIUM ( $n=226)$

\begin{tabular}{lll}
\hline Characteristics & n & \% \\
\hline Age (years) & 24 & 1.01 \\
Gender & 66 & \\
Male & 160 & 29.2 \\
Female & & 70.8 \\
Year of study & 71 & \\
$\quad$ Year 3 & 84 & 31.4 \\
Year 4 & 71 & 37.2 \\
Year 5 & 5000 & 31.4 \\
Household income & 40 & $7000^{*}$ \\
Monthly expenditure & & $20.0^{*}$ \\
Primary purpose of smartphone usage & \\
Academic performance task & 25 & 11.1 \\
Educational & 18 & 8.0 \\
Games & 16 & 7.1 \\
Others & 11 & 4.9 \\
Social Networking & 156 & 69.0 \\
Average number of hours of smartphone $u s a g e$ per day & \\
<1 h & 4 & 1.7 \\
1-2 h & 11 & 4.9 \\
3-4 h & 83 & 36.7 \\
5-6 h & 61 & 27.0 \\
>6 h & 67 & 29.6 \\
\hline
\end{tabular}

*Median (IQR). IIUM: International Islamic University Malaysia

Table 2: Psychological health of the clinical year students in Kulliyyah of medicine $(n=226)$

\begin{tabular}{llll}
\hline Domain & Year of study & n & $\begin{array}{l}\text { Mean (SD) } \\
\text { QOL* Scores }\end{array}$ \\
\hline Psychological Health & Year 3 & 71 & $57.73(16.05)$ \\
& Year 4 & 84 & $61.33(16.49)$ \\
& Year 5 & 71 & $60.34(14.40)$ \\
& Total & 226 & $59.89(15.73)$ \\
\hline
\end{tabular}

*Quality of life
Relationship between socio-demographic characteristics and smartphone addiction among clinical year students of Kulliyyah of medicine

The only significant factor related to smartphone addiction was the primary purpose of smartphone usage, and more than two-thirds of both groups of students who were addicted as well as not addicted chose social networking as their primary purpose of smartphone usage $(p=0.037)$. Otherwise, other factors such as gender, year of study, household income, monthly expenditure, and average number of hours of smartphone usage per day posed no significant relation to smartphone addiction among respondents, as shown in Table 3.

Following multiple logistic regression analysis, the primary purpose of smartphone usage remained a significant factor for smartphone addiction among clinical year medical students in IIUM Kuantan. Respondents who had chosen games as their primary purpose of smartphone usage were $88 \%$ less likely to be related with smartphone addiction ( $\mathrm{p}=0.009,95 \% \mathrm{CI}$ : 0.025-0.595) compared to those who used it for academic performance tasks, as shown in Table 4. Respondents who were not addicted to smartphones reported significantly better psychological quality of life scores compared to those who were addicted $(\mathrm{p}<0.001)$ as shown in Table 5.

\section{DISCUSSION}

The prevalence of smartphone addiction among clinical years medical students at International Islamic University (IIUM) was 51\%. This finding was similar to an unpublished research done among the preclinical medical students of IIUM in which smartphone addiction covered about half of the population studied [6]. However, Ramesh et al. discovered that only $36.8 \%$ of medical students in India had smartphone addiction [7]. Meanwhile, in China, the prevalence of smartphone addiction among medical students was found to be $29.8 \%$ [8]. In both studies, only one-third of their population was addicted to a smartphone in which it is lower compared to our study. Comparably, another university in Malaysia showed that the prevalence of smartphone addiction among their medical students was 46.9\% [9], which is still slightly lower than IIUM. Therefore, the students in IIUM have a higher prevalence of addiction as compared to other students in different institutions.

Compared with age-comparable individuals and the general U.S. population, Dyrbye et al. concluded that medical students have poorer mental quality of life [10]. However, in our study, IIUM medical students had the good mental quality of life scores with the mean score 59.89 . (SD; 15.72).

Previous studies discovered that the prevalence of stress is high among $4^{\text {th }}$-year medical students $[11,12]$. However, in our study, among all the medical students, year 4 medical students had the best psychological health with the mean score of 61.33 (SD; 16.49), followed by year 5 with mean scores of 60.34 (SD 14.40) and the worst was year 3 with mean scores of 57.73 (SD; 10.05). This result may be due to the fact that the year 4 students were in their elective posting period during the data collection of this study, while year 3 and year 5 students are in their end of block examination phase. The differences in the scores among medical schools could be because of the variety of each program structure.

The primary purpose of using smartphone played a significant role in smartphone addiction, and after multiple logistic regression analysis, it was proven to remain a significant factor for smartphone addiction among clinical year medical students in IIUM Kuantan. We found that among respondents who had smartphone addiction, the majority (70\%) of them used their smartphones mainly for social networking. This finding is in line with previous studies $[13,14]$. In contrast, it was noted in an unpublished observation by Pasi et al. that the primary purpose for using a smartphone among IIUM's pre-clinicalyears medical students was also for social networking, but this was statistically unrelated to smartphone addiction. Longer duration using a smartphone was a significant factor in their study instead [6]. 
Table 3: Relationship between socio-demographic characteristics and smartphone addiction among clinical year students of Kulliyyah of medicine $(n=226)$

\begin{tabular}{|c|c|c|c|}
\hline \multirow[t]{2}{*}{ Characteristics } & \multicolumn{2}{|c|}{ Addiction status } & \multirow[t]{2}{*}{ p-value } \\
\hline & Addicted & Not addicted & \\
\hline Gender & & & 0.06 \\
\hline Male & $40(34.8)$ & $26(23.4)$ & \\
\hline Female & $75(65.2)$ & $85(76.6)$ & \\
\hline Year of study & & & $0.78^{\mathrm{a}}$ \\
\hline Year 3 & $36(31.3)$ & $35(31.5)$ & \\
\hline Year 4 & 45 (39.1) & $39(35.1)$ & \\
\hline Year 5 & $34(29.6)$ & $37(33.3)$ & \\
\hline Age & $23.84(1.05)^{* *}$ & $23.85(0.99)^{* *}$ & $0.98^{\mathrm{b}}$ \\
\hline Household income (RM) & $5000(7000)^{*}$ & $4700(7500)^{*}$ & $0.06^{c}$ \\
\hline Monthly expenditure (RM) & $35(20)^{*}$ & $40(20)^{*}$ & $0.64^{c}$ \\
\hline Primary purpose of smartphone usage & & & $0.04^{\mathrm{a}}$ \\
\hline Academic performance task & $8(7.0)$ & $17(15.3)$ & \\
\hline Educational & $8(7.0)$ & $10(9.0)$ & \\
\hline Games & $13(11.3)$ & $3(2.7)$ & \\
\hline Others & $5(4.3)$ & $6(5.4)$ & \\
\hline Social Networking & $81(70.4)$ & $75(67.6)$ & \\
\hline Average number of hours of smartphone usage per day & & & $0.10^{\mathrm{a}}$ \\
\hline$<1 \mathrm{~h}$ & $1(0.9)$ & $3(2.7)$ & \\
\hline $1-2 \mathrm{~h}$ & $4(3.5)$ & $7(6.3)$ & \\
\hline $3-4 \mathrm{~h}$ & $35(30.4)$ & $48(43.2)$ & \\
\hline $5-6 \mathrm{~h}$ & $35(30.4)$ & $26(23.4)$ & \\
\hline$>6 \mathrm{~h}$ & $40(34.8)$ & $27(24.3)$ & \\
\hline
\end{tabular}

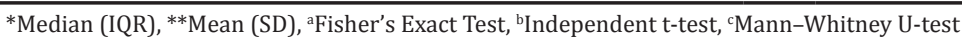

Table 4: Multiple logistic regression model between primary purpose of smartphone usage and smartphone addiction $(n=226)$

\begin{tabular}{lll}
\hline Characteristic & OR* $(\mathbf{9 5 \%} \mathbf{C I} * \mathbf{*})$ & p-value \\
\hline $\begin{array}{l}\text { Primary purpose of } \\
\text { smartphone usage }\end{array}$ & & \\
$\quad \begin{array}{l}\text { Academic performance } \\
\text { task }\end{array}$ & 1 & 0.136 \\
$\quad$ Educational & $0.44(0.118-1.643)$ & 0.222 \\
$\quad$ Games & $0.12(0.025-0.595)$ & 0.009 \\
$\quad$ Others & $0.55(0.113-2.707)$ & 0.466 \\
$\quad$ Social Networking & $0.44(0.171-1.111)$ & 0.082 \\
\hline *Odds ratio, ${ }^{* *}$ Confidence interval & &
\end{tabular}

Table 5: Relationship between smartphone addiction and psychological health $(n=226)$

\begin{tabular}{lllll}
\hline Domain & $\begin{array}{l}\text { Addiction } \\
\text { status }\end{array}$ & $\boldsymbol{n}$ & $\begin{array}{l}\text { Mean (SD) QOL } \\
\text { scores }\end{array}$ & p-value \\
\hline $\begin{array}{l}\text { Psychological } \\
\text { domain }\end{array}$ & & & & $<0.001$ \\
& Addicted & 115 & $55.21(15.20)$ & \\
& Not addicted & 111 & $64.74(14.83)$ & \\
\hline
\end{tabular}

*Quality of life

A recent survey discovered that respondents who used smartphones for entertainment purposes such as social networking or games were more likely to be addicted, while those who used smartphones for academic purposes were not [15]. Interestingly, this study showed that IIUM medical students were the opposite. Those who used smartphones for games were $88 \%$ less likely to acquire smartphone addiction as compared to those who used their smartphones for academic purposes. This could be because the data collection period coincided with periods of study weeks and examinations especially for respondents in year 3 and 5, thus it might have affected the results in such a way that most students used their smartphones and other mobile devices to study as it offered quick access to information. However, this might not be a good point because students with smartphone addiction have reduced level of self-regulated learning [16] because of disruptions by other phone applications while they were studying and they were not being selfdisciplined with their smartphone studying arrangements.

Other factors such as gender, year of academic study, household income, time spent using smartphone, and monthly expenditure on the smartphone were not significantly related to smartphone addiction in this study. They were no statistically significant differences between genders. Both male and female were equally addicted to smartphones which are supported by other findings from recent studies $[8,17,18]$ although according to a research done among the students of a medical university in South India, males were twice more addicted to smartphones [7] while other studies revealed the opposite [19]. Referring to the academic year of study, year 4 students had a slightly higher percentage of smartphone addiction (39\%) compared to year $3(31 \%)$ and year $5(30 \%)$. For household income, previous studies $[20,21]$ had shown that students from families with higher income spent more money and time on their smartphones. This is similar with our study where the students with smartphone addiction had slightly higher income as compared to the non-addicted students but this result was not significant.

The time spent using smartphone also had no relationship with smartphone addiction although most of the smartphone addict spent more than $6 \mathrm{~h}$ on their smartphones (35\%). This differs with the finding from the unpublished observations of Pasi et al. which showed a statistically significant relation $(\mathrm{p}=0.001)$ between time spent on smartphone and its addiction whereby smartphone addiction is highest among those who spent more than $6 \mathrm{~h}$ on their smartphone (72\%) [6]. While Chen et al. [22] linked higher monthly expenditure with smartphone addiction, this study showed that respondents with smartphone addiction spent less amount of money on things related to their smartphones such as data, applications, and accessories.

To exert the importance of this study, we found that smartphone addiction was positively related to the lower score of the psychological domain of quality of life $(p<0.001)$. The student with smartphone addiction had poorer psychological and mental health. A study showed that poor psychological health is strongly associated with severe anxiety [23]. This finding was in line with the previous studies which linked smartphone addiction with depression, anxiety, emotional 
lability, decreased sleep quality, stress, loneliness, and problems in campus life and personal relationships [3,8,24-28].

\section{CONCLUSION}

The prevalence of smartphone addiction among clinical year medical students of IIUM Kuantan Campus was 51\%, which is comparable with previous studies. The factors affecting smartphone addiction played a role in identifying and combatting this issue. This study found that social networking was a significant factor related to smartphone addiction. Moreover, medical students with smartphone addiction had poorer psychological health. As work in the medical field is mentally demanding, future doctors need to acquire good psychological wellbeing. Therefore, creating awareness on campus, such as in the form of health campaigns is imperative to curb this rising problem.

\section{ACKNOWLEDGMENT}

This study was funded by the IIUM Research Initiative Grant Scheme (RIGS17-046-0639).

\section{AUTHORS' CONTRIBUTIONS}

All authors have contributed to this work.

\section{CONFLICTS OF INTEREST}

The authors declare that they have no conflicts of interest

\section{REFERENCES}

1. Lee YK, Chang CT, Lin Y, Cheng ZH. The dark side of smartphone usage: Psychological traits, compulsive behavior and technostress. Comput Hum Behav 2014;31:373-83.

2. Grant JE, Potenza MN, Weinstein A, Gorelick DA. Introduction to behavioral addictions. Am J Drug Alcohol Abuse 2010;36:233-41.

3. Boumosleh JM, Jaalouk D. Depression, anxiety, and smartphone addiction in university students a cross sectional study. PLoS One 2017;12:e182239.

4. Aloman MJ, Abdi AM, Zaman S, Abdi HM, Quicho MA. Impact of lifestyle on the occurence of anxiety among residents of United Arab Emirates. Int J Pharm Pharm Sci 2018;10:153-6.

5. Kwon M, Kim DJ, Cho H, Yang S. The smartphone addiction scale: Development and validation of a short version for adolescents. PLoS One 2013;8:e83558.

6. Pasi H, Mohd RR, Rahman JA, Aziz A, Hanim K, Nasreen HE, et al. Prevalence of Smartphone Addiction and its Related Factors among Pre-clinical Students at IIUM Kuantan Campus. $2^{\text {nd }}$ ed. Sabah Regional Public Health Conference 11-14 October 2016.

7. Ramesh AK, Karkal R, Nafisa D, Kini G, Chandrashekaran P. Smartphone addiction among students of medical university in South India: A cross-sectional study. Ann Int Med Dent Res 2018;4:PY01-4.

8. Chen B, Liu F, Ding S, Ying X, Wang L, Wen Y, et al. Gender differences in factors associated with smartphone addiction: A cross-sectional study among medical college students. BMC Psychiatry 2017;17:341.

9. Ching SM, Yee A, Ramachandran V, Lim SM, Wan Sulaiman WA, Foo YL, et al. Validation of a Malay version of the smartphone addiction scale among medical students in Malaysia. PLoS One 2015;10:e139337.

10. Dyrbye LN, Thomas MR, Massie FS, Power DV, Eacker A, Harper W, et al. Burnout and suicidal ideation among U.S. Medical students. Ann
Intern Med 2008;149:334-41

11. Yusoff MS, Rahim AF, Yaacob MJ. Prevalence and sources of stress among Universiti Sains Malaysia medical students. Malays J Med Sci 2010;17:30-7

12. Eva EO, Islam MZ, Mosaddek AS, Rahman MF, Rozario RJ, Iftekhar AF, et al. Prevalence of stress among medical students: A comparative study between public and private medical schools in Bangladesh. BMC Res Notes 2015;8:327.

13. Lopez-Fernandez O, Honrubia-Serrano L, Freixa-Blanxart M, Gibson W. Prevalence of problematic mobile phone use in British adolescents. Cyberpsychol Behav Soc Netw 2014;17:91-8.

14. Haug S, Castro RP, Kwon M, Filler A, Kowatsch T, Schaub MP, et al. Smartphone use and smartphone addiction among young people in Switzerland. J Behav Addict 2015;4:299-307.

15. Jeong SH, Kim H, Yum JY, Hwang Y. What type of content are smartphone users addicted to? SNS vs. games. Comput Hum Behav 2016;54:10-7

16. Lee J, Cho B, Kim Y, Noh J. Smartphone addiction in university students and its implication for learning. In: Chen G, Kumar V, Huang RK, Kong S, editors. Emerging Issues in Smart Learning. Lecture Notes in Educational Technology. Berlin, Heidelberg: Springer; 2015. p. 297-305.

17. Haque M, Rahman NA, Majumder MA, Haque SZ, Kamal ZM, Islam Z, et al. Internet use and addiction among medical students of Universiti Sultan Zainal Abidin, Malaysia. Psychol Res Behav Manag 2016;9:297-307.

18. Hawi NS, Samaha M. To excel or not to excel: Strong evidence on the adverse effect of smartphone addiction on academic performance. Comput Educ 2016;98:81-9.

19. Mok JY, Choi SW, Kim DJ, Choi JS, Lee J, Ahn H, et al. Latent class analysis on internet and smartphone addiction in college students. Neuropsychiatr Dis Treat 2014;10:817-28.

20. Zulkefly SN, Baharudin R. Mobile phone use amongst students in a university in Malaysia: Its correlates and relationship to psychological health. Eur J Sci Res 2009;37:206-18.

21. Chukwuere JE, Mbukanma I, Enwereji PC. The financial and academic implications of using smartphones among students: A quantitative study. J Econ Econ Educ Res 2017;18:1-26.

22. Chen L, Yan Z, Tang W, Yang F, Xie X, He J. Mobile phone addiction levels and negative emotions among Chinese young adults: The mediating role of interpersonal problems. Comput Hum Behav 2016;55:856-66.

23. Venkataraman R, Vikhram R, Pandian RS, Teli G, Shrestha N. The relation between internet, depression, self-esteem and social attachment on cognitive function of health care individuals. Int J Pharm Pharm Sci 2017;9:144-9

24. Kim J, LaRose R, Peng W. Loneliness as the cause and the effect of problematic internet use: The relationship between internet use and psychological well-being. Cyberpsychol Behav 2009;12:451-5.

25. Hwang KH, Yoo YS, Cho OH. Smartphone overuse and upper extremity pain, anxiety, depression, and interpersonal relationships among college students. J Korea Contents Assoc 2012;12:365-75.

26. Choi HS, Lee HK, Ha JC. The influence of smartphone addiction on mental health, campus life and personal relations-focusing on $\mathrm{K}$ university students. J Korean Data Inf Sci Soc 2012;23:1005-15.

27. Demirci K, Akgönül M, Akpinar A. Relationship of smartphone use severity with sleep quality, depression, and anxiety in university students. J Behav Addict 2015;4:85-92.

28. Samaha M, Hawi NS. Relationships among smartphone addiction, stress, academic performance, and satisfaction with life. Comput Hum Behav 2016;57:321-5. 